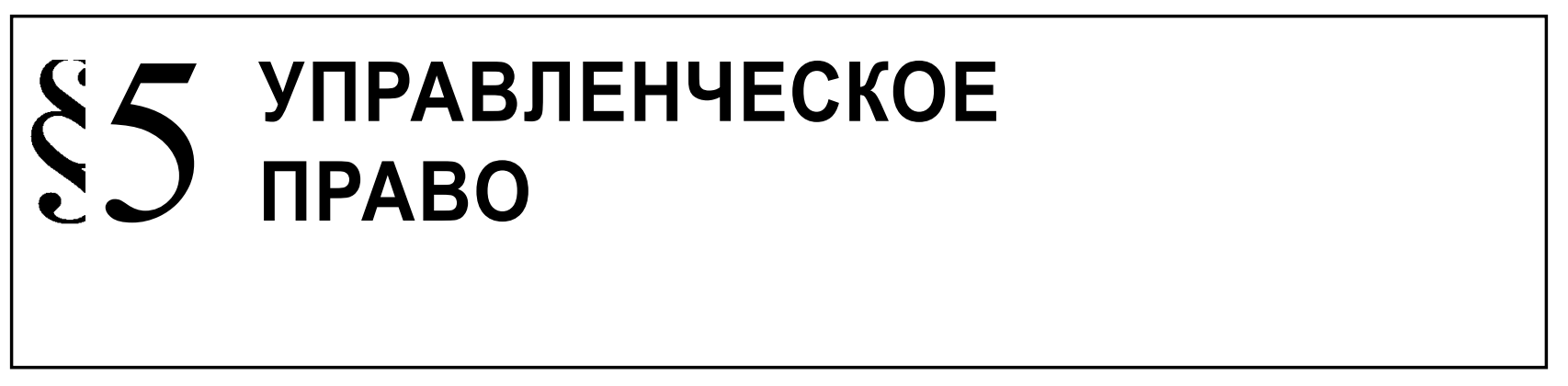

Кудрявцев В.В.

\title{
О НЕКОТОРЫХ ВОПРОСАХ КОНСТИТУЦИОННО-ПРАВОВОГО РЕГУЛИРОВАНИЯ ПРАВА ГРАЖДАН И ИХ ОБЪЕДИНЕНИЙ НА УЧАСТИЕ В ФОРМИРОВАНИИ ПРЕДСТАВИТЕЛЬНЫХ ОРГАНОВ МУНИЦИПАЛЬНЫХ ОБРАЗОВАНИЙ В РОССИЙСКОЙ ФЕДЕРАЦИИ
}

Аннотация: Предметом исследования некоторые тенденции и новеллы в российском законодательстве, касающиеся изменения в России порядка формирования представительных органов таких муниципальных образований, как городские округа и муниципальные районы, и участия в этой процедуре граждан Российской Федерации и их объединений. их влияние на право местного населения на участие в формировании органов местного самоуправления, которое, в свою очередь, является важнейшим элементом и составляющей права на осуществление местного самоуправления. Рассматривается динамика и логическая цепочка последних изменений в законодательстве по этой тематике. Проводится анализ различны точек зрения по проблематике. Анализируется практика применения норм федерального законодательства в области муниципальных выборов с позиции права на участие в формировании органов местного самоуправления. В исследовании нами используются специальные юридические методы познания. В частности, применяется формально-юридический метод, посредством которого нами уясняется порядок применения и использования конституционно-правовой базы, регулирующей порядок формирования органов местного самоуправления в России, для определения юридических понятий, связанных с участием местного населения в формировании органов местного самоуправления, для классификации способов формирования местных органов. Используется метод правового толкования, с помощью которого нами проводится самостоятельное разъяснение сущности конституционно-правовых норм, касающихся способов формирования местных органов власти. Последние изменения в федеральном законодательстве, касающиеся изменения порядка формирования представительных органов муниципальных образований до сих пор не были предметом комплексного анализа в юридической науке. Автором анализируются данные изменения в контексте с предыдущими законодательными тенденциями и новеллами в этой сфере. Сформулирован вывод о необходимости соотнесения рассматриваемых правовых институтов в соответствии с принципами верховенства и делается акцент на ряде конституционных принципов местного самоуправления, в соответствии с которыми делаются соответствующие выводы о формировании необходимой правовой политики в вопросах права граждан на участие в формировании представительных органов муниципальных образований. Высказываются рекомендации, направленные на усиление демократизации процесса формирования данных органов местного самоуправления.

Ключевые слова: Местное самоуправление, Местная власть, Местное население, Граждане, Общественные объединения, Политические партии, Муниципальные выборы, Представительные органы, Избирательная система, муниципальное образование. 
П роблема формирования в России эффективной системы местного самоуправления является одной из ключевых в свете современного курса конституционного развития. Так, в своем последнем Послании Федеральному собранию Президент РФ В.В.Путин отметил необходимость большей ответственности органов местного самоуправления и их подотчетности населению таким образом, «чтобы до них можно было дотянуться рукой». Как подчеркивает Президент, данные изменения в местном самоуправлении должны происходить посредством повышения политической конкуренции на местном уровне ${ }^{1}$. В то же время, данная реформа невозможна без конкретизации принципов местного самоуправления. В этой связи, представляется актуальным рассмотреть внесенные в последние годы в федеральное законодательство изменения, касающиеся применения избирательных систем на муниципальном уровне, и моделей формирования органов местного самоуправления, которые в ряде случаев несколько сужают возможности субъектов РФ в выборе того или иного способа формирования местной власти.

Представляется достаточно спорным значительное внедрение элементов пропорциональной избирательной системы на местных выборах. В последние годы в российском законодательстве наблюдались противоречивые тенденции, касающиеся установления той или иной избирательной системы на местном уровне. В 2011 году в Федеральный закон «Об общих принципах организации местного самоуправления в Российской Федерации» были внесены изменения, согласно которым в представительных органах городских округов и муниципальных районов с численностью не менее 20 депутатов не менее 50\% депутатского корпуса должно избираться по пропорциональной системе $^{2}$. В 2013 году в данные нормы внесли изменения, согласно которым для представительных органов этих муниципальных образований была

\footnotetext{
1 Владимир Путин обратился с посланием к Федеральному собранию РФ // Российская газета. 2013. №6258 от 13 декабря 2013 года. С.2.

2 Федеральный закон от 20.03.2011 «О внесении изменений в статьи 35 и 38 Федерального закона «Об основных гарантиях избирательных прав и права на участие в референдуме граждан Российской Федерации» и Федеральный закон «Об общих принципах организации местного самоуправления в Российской Федерации» в связи с применением пропорциональной избирательной системы на выборах депутатов представительных органов муниципальных районов и городских округов» // СЗ РФ, 28.03.2011. №13. Ст.1685.
}

установлена минимальная планка в 25\% депутатов, избираемых по партийным спискам, и планка в 15 депутатов представительного органа, при формировании которого может применяться пропорциональная избирательная система. Кроме того для субъектов РФ введена возможность установления чисто мажоритарной избирательной системы по усмотрению муниципальных образований этих субъектов $\mathrm{P}^{3}$. Таким образом, у муниципальных образований теоретически появляется широкий спектр выбора той или иной системы формирования представительного органа.Стоит отметить, что столь частые изменения в ФЗ-№131 в основном обосновывались законодателем необходимостью, в первую очередь, развития тех или иных политических институтов на местном уровне, а не необходимостью развития местного самоуправления.

Если говорить о практическом воплощении данных норм в различных субъектах РФ, то стоит отметить что на сегодняшний день в большинстве муниципальных образований применяется смешанная избирательная система, при которой половина депутатов представительного органа избирается по партийным спискам, а другая половина по одномандатным округам. Лишь в некоторых регионах, таких как Дагестан и Карачаево-Черкессия, применяется исключительно пропорциональная система. В тоже время, пока в муниципальных образованиях не наблюдается тенденции отказа от данной системы или сокращения доли избираемых по ней депутатов до 25\% либо вовсе перехода к мажоритарной системе с избранием депутатов исключительно по округам. На практике последняя система была наиболее востребованной на местном уровне 4 . Однако последние годы перечисленные типы муниципальные образования лишены этой возможности.

По мнению инициаторов изменений, вносимых в три года назад, участие политических партий в представительном органе местного самоуправления должно способствовать повышению политического профессионализма данного органа, активизации институтов гражданского общества в системе местного самоуправления, а также более

\footnotetext{
Федеральный закон от 02.11.2013 №303-Ф3 «О внесении изменений в отдельные законодательные акты Российской Федерации» // С3 РФ. 0411.2013. №44. ст.5642

4 Любарев А.Е. О проблемах использования пропорциональной избирательной системы на муниципальных выборах//Конституционное и муниципальное право, 2011. № 11. С.68.
} 
плодотворному его взаимодействию с органами государственной власти.

Однако, нам представляется, что при оценке упомянутых новелл необходимо их соотнесение со спецификой местного самоуправления и с готовностью населения к реализации данной нормы. Кроме того, нужно учитывать, что одним из главных принципов и отличительных черт местного самоуправления является самостоятельность его осуществления населением. Поэтому будет правильным, если при внесении тех или иных изменений в законодательство, касающихся регулирования права граждан и их объединений на участие в формировании органов местного самоуправления, в той или иной степени будет учитываться позиция муниципальных образований и, в особенности, мнение местного населения. Современное правовое государство, построение которого является для России одной из основополагающих задач, по мнению ряда исследователей, предполагает наибольшую степень свободы для человека и гражданина 5 .

Вместе с тем высокая степень свободы - это не только ответственное отношение к своим правам и обязанностям со стороны всех участников общественных отношений и их добросовестная реализация, но и эффективная реализация принципа верховенства права, и в особенности конституционных принципов ${ }^{6}$. И в свете новелл последних лет встает вопрос необходимости соблюдения верховенства конституционного принципа самостоятельности местного самоуправления и самостоятельности его осуществления населением.

Возвращаясь к упомянутым последним изменениям Федерального закона №131-Ф3 представляется справедливым мнение В. И. Васильева и А. Е. Помазанского ${ }^{7}$ о том, что в небольших по численности избирателей муниципальных образованиях с малым числом депутатов в представительном органе практически невозможно распределение мандатов согласно количеству голосов, полученных партийными списками. Кроме того, в результате изменений, внесенных в 2012 в Федеральный за-

\footnotetext{
5 Мацкевич А.В.Функции юридической ответственности в современном обществе: понятие, система, тенденции развития //Рос. следователь. 2006. №12. С.63.

6 Михеева Т.Н. О принципе верховенства права на современном этапе развития правового государства // Закон и право.2013. №9. С.29.

Васильев В.И.,Помазанский А.Е., Законодательное регулирование избирательных систем, применяемых на муниципальных выборах// Журнал российского права. 2010. №8. С. 18.
}

кон «0 политических партиях», минимальный порог численности политических партий был снижен до 500 человек, в результате чего резко увеличилось количество партий, имеющих право участвовать в выборах всех уровней. Следовательно, значительно возрастает вероятность прохождения в представительный орган муниципального образования значительно большего количества политических партий. В этой связи возникает вероятность минимальной разницы в количестве мандатов между списком, набравшим большинство голосов избирателей, и списками, набравшими минимальное количество голосов, которое необходимо для допуска партийных списков к распределению депутатских мандатов. Таким образом, во-первых, искажается сама сущность пропорциональной избирательной системы, так как в данном случае происходит распределение депутатских мандатов не пропорционально степени их поддержки местным населением, выраженной в определенном проценте голосов избирателей. Во-вторых, происходит реальное ограничение права граждан и их объединений на участие в формировании представительных органов муниципальных образований, потому что списки партий, которые получили наибольшую поддержку избирателей, не могут получить больше на 1 или 2 мандата, чем остальные списки партий. Следовательно, поддержка этой партии местным населением не находит своего реального отражения при распределении депутатских мандатов в представительном органе, так как незначительно превосходит количество депутатских мандатов, получаемых списками партий, пользующихся значительно меньшей поддержкой населения. Кроме того, вполне допустимой становится ситуация, при которой списки политических партий, имеющие разницу в 10-12 \% голосов избирателей, будут иметь незначительные различия в количестве распределяемых между данными списками мандатов. Тем самым, по сути, искажается сама суть института выборов, как способа участия граждан и их объединений в формировании органов местного самоуправления, который предполагает наличие побеждающих и проигрывающих сторон вследствие выражения волеизъявления избирателей. И, наконец, в-третьих, при большом количестве представителей малых партий в представительном органе и отсутствии по-настоящему пропорционального распределения мандатов между ними, возрастает вероятность превращения представительного органа в арену политического противостояния. 
Представляется, что муниципальный уровень власти с его небольшими, по сравнению с государственными ресурсами, возможностями - это не то поле деятельности, где политические партии могут реализовать свои фундаментальные и крупномасштабные задачи. Не случайно в статье 3 Федерального закона «0 политических партиях» предусмотрено создание только общефедеральных партий с правом формирования своих региональных отделений в пределах субъектов Российской Федерации, а не территорий муниципальных образований. Это не значит, что вопросы организации и функционирования местного самоуправления в России не являются предметом, составляющим политический интерес партий. Как замечает А. А.Уваров ${ }^{8}$, механизмом воплощения этого интереса, адекватным статусу политических партий, служит их законотворческая деятельность через депутатов - членов этих партий в Государственной Думе Российской Федерации и законодательных (представительных) органах субъектов Российской Федерации. Сам масштаб задач, решаемых политическими партиями не вполне оправдывает их участие в борьбе за депутатские места в представительных органах местного самоуправления либо в формировании других местных выборных органов.

Кроме того, внедрение пропорциональной избирательной системы на муниципальных выборах и усиление роли политических партий в процессе формирования органов местного самоуправления оказывают существенное влияние на правовой статус иностранных граждан, постоянно проживающих на территории муниципальных образований. На сегодня в России сформирована законодательная база, касающаяся предоставления и реализации права иностранным гражданам на участие в формировании органов местного самоуправления. Данное право для иностранцев выражается в их возможности голосовать на любых местных выборах, выступать в качестве наблюдателей, возможности выдвижения своих кандидатур на выборах депутатов представительных органов, а также главы муниципального образования и местной администрации, как при системе прямых выборов, так и при их избрании представительным органом муниципального образования. Это право гарантируется иностранным гражданам целым рядом ключевых федеральных законов и на

8 Уваров А.А. Местное самоуправление и гражданское общество // Конституционное и муниципальное право. 2008. №15. C.8. основании международных договоров, заключенных Российской Федерацией. Как гласит п. 10 ст. 4 Федерального закона «Об основных гарантиях избирательных прав и права граждан на участие в референдуме граждан РФ»: «На основании международных договоров и в порядке, установленном законом, иностранные граждане, постоянно проживающие на территории соответствующего муниципального образования, имеют право избирать и быть избранными в органы местного самоуправления». Данное право также закрепляется ч. 1 ст. 3 Федерального закона «Об общих принципах организации местного самоуправления в Российской Федерации», ч. 2 ст. 12 Федерального закона «О правовом положении иностранных граждан в Российской Федерации», ст. 3 Федерального закона «Об обеспечении конституционных прав граждан Российской Федерации избирать и быть избранными в органы местного самоуправления». Право голосовать и выдвигать своих кандидатов на местных выборах иностранцы имеют на основании ратифицированных Российской Федерацией международных договоров.

Иностранные граждане, постоянно проживающие в Российской Федерации в конкретном муниципальном образовании, также относятся к местному населению, чьи интересы и нужды, относящиеся к вопросам местного значения, должны решать формируемые населением органы местного самоуправления. Посредством же межгосударственных соглашений, по сути, происходит обоюдное выражение суверенной воли Российской Федерации и других государств на признание граждан одного государства местным населением в другом и, соответственно, признание за ним естественного в данном случае права на участие в формировании органов местного самоуправления. В свою очередь, право на участие в формировании органов местного самоуправления является важнейшей составляющей права на осуществление местного самоуправления. Участие иностранных граждан в муниципальных выборах, в случаях, предусмотренных международными договорами, заключенными Российской Федерацией, нацелено на их вовлечение в эффективное и полное разрешение вопросов местного значения в интересах местного населения, частью которого выступает данная категория иностранных граждан, но ни в коей мере не в разрешение общегосударственных вопросов. Представляется, что данная возможность участия иностранных граждан в формировании местных органов сама по себе не 
является нарушением конституционного принципа суверенитета России.

В свою очередь, не допускается членство иностранных граждан в общефедеральных политических партиях. которые нацелены на решение общегосударственных задач. Участие иностранных граждан при внедрении пропорциональной избирательной системы на муниципальных выборах в значительной системе ставится в зависимость от воли политической партии, руководящий орган которой может либо принять, либо не принять ре- шение о включении иностранного гражданина в избирательный список политической партии..

Вышеизложенное свидетельствует о нецелесообразности применения пропорциональной системы на местных выборах. Необходимо исходить из принципа самостоятельности населения в осуществлении местного самоуправления и законодательно закрепить обязательность вынесения на местный референдум вопроса о выборе мажоритарной или смешанной системы на выборах представительных органов.

\section{Библиография:}

1. Владимир Путин обратился с посланием к Федеральному собранию РФ// Российская газета.2013.№6258 от 13 декабря 2013 года. С.2

2. Любарев A.Е. О проблемах использования пропорциональной избирательной системы на муниципальных выборах // Конституционное и муниципальное право,2011 № 11 С.68.

3. Мацкевич А.В.Функции юридической ответственности в современном обществе: понятие, система, тенденции развития // Рос.следователь.2006.№12.С.63

4. Михеева Т.Н. О принципе верховенства права на современном этапе развития правового го-сударства/ Закон и право 2013 №9 С.29

5. Васильев В.И., Помазанский А.Е.Законодательное регулирование избирательных систем, применяемых на муниципальных // Журнал российского права 2010 № 8 С.18

6. Уваров А.А.Местное самоуправление и гражданское общество // Конституционное и муни-ципальное право 2008 №15 С. 8

7. Лапин А.Е., Петрова Ю.А. К вопросу о реализации полномочий представительных органов местного самоуправления в Российской Федерации // Административное и муниципальное право.-2011.-4.-С. 24-33.

8. Трофимов В.В. Участие структур гражданского общества в правообразующих правоотношениях как форма выражения народовластия // NB: Вопросы права и политики.-2012.-5.-C. 147-170. DOI: 10.7256/2305-9699.2012.5.364. URL: http://www.e-notabene.ru/lr/article_364.html

9. Гуляихин В.Н. Правовой менталитет российских граждан // NB: Вопросы права и политики.-2012.4.-C. 108-133. DOI: 10.7256/2305-9699.2012.4.310. URL: http://www.e-notabene.ru/lr/article_310.html

10. Гуляихин В.Н. Структурно-функциональные особенности различных состояний правосознания человека // NB: Вопросы права и политики.-2012.-2.-C. 90-116. DOI: 10.7256/2305-9699.2012.2.153. URL: http://www.e-notabene.ru/lr/article_153.html

11. Гуляихин В.Н. Психосоциальные формы правового нигилизма человека // NB: Вопросы права и политики.-2012.-3.-C. 108-148. DOI: 10.7256/2305-9699.2012.3.240. URL: http://www.e-notabene.ru/lr/ article_240.html

12. Щупленков О.В., Щупленков Н.О. Трансформация власти в процессе построения гражданского общества в России // NB: Проблемы общества и политики.-2013.-9.-C. 20-88. URL: http://www.e-notabene. $\mathrm{ru} / \mathrm{pr} / \mathrm{article} \_9053 . \mathrm{html}$

13. Щупленков О.В., Щупленков Н.О. Идеи солидаризма в концепции построения гражданского общества в России // NB: Проблемы общества и политики.-2013.-8.-C. 72-137. URL: http://www.e-notabene.ru/ pr/article_8750.html

14. М. М. Вахитов Участие граждан Российской Федерации в региональном правотворчестве: природа и механизмы реализации // Политика и Общество.-2011.-11.-С. 113-127.

\section{References:}

1. Vladimir Putin obratilsya s poslaniem k Federal'nomu sobraniyu RF// Rossiiskaya gaze-ta.2013.№6258 ot 13 dekabrya 2013 goda. S.2 
Административное и муниципальное право 3 (75) • 2014

2. Lyubarev A.E. 0 problemakh ispol'zovaniya proportsional'noi izbiratel'noi sistemy na munitsipal'nykh vyborakh // Konstitutsionnoe i munitsipal'noe pravo,2011 № 11 S.68.

3. Matskevich A.V.Funktsii yuridicheskoi otvetstvennosti v sovremennom obshchestve: ponyatie, sistema, tendentsii razvitiya // Ros.sledovatel'.2006.№12.S.63

4. Mikheeva T.N. O printsipe verkhovenstva prava na sovremennom etape razvitiya pravovogo go-sudarstva/ Zakon i pravo 2013 №9 S.29

5. Vasil'ev V.I., Pomazanskii A.E.Zakonodatel'noe regulirovanie izbiratel'nykh sistem, primenyaemykh na munitsipal'nykh // Zhurnal rossiiskogo prava 2010 № 8 S.18

6. Uvarov A.A.Mestnoe samoupravlenie i grazhdanskoe obshchestvo // Konstitutsionnoe i muni-tsipal'noe pravo 2008 №15 S. 8

7. Lapin A.E., Petrova Yu.A. K voprosu o realizatsii polnomochii predstavitel'nykh organov mestnogo samoupravleniya v Rossiiskoi Federatsii // Administrativnoe i munitsipal'noe pravo.-2011.-4.-C. 24-33.

8. Trofimov V.V. Uchastie struktur grazhdanskogo obshchestva $\mathrm{v}$ pravoobrazuyushchikh pravootnosheniyakh kak forma vyrazheniya narodovlastiya // NB: Voprosy prava i politiki.-2012.-5.-C. 147-170. DOI: 10.7256/2305-9699.2012.5.364. URL: http://www.e-notabene.ru/lr/article_364.html

9. Gulyaikhin V.N. Pravovoi mentalitet rossiiskikh grazhdan // NB: Voprosy prava i politiki.-2012.-4.-C. 108133. DOI: 10.7256/2305-9699.2012.4.310. URL: http://www.e-notabene.ru/lr/article_310.html

10. Gulyaikhin V.N. Strukturno-funktsional'nye osobennosti razlichnykh sostoyanii pravosoznaniya cheloveka // NB: Voprosy prava i politiki.-2012.-2.-C. 90-116. DOI: 10.7256/2305-9699.2012.2.153. URL: http://www.enotabene.ru/lr/article_153.html

11. Gulyaikhin V.N. Psikhosotsial'nye formy pravovogo nigilizma cheloveka // NB: Voprosy prava i politiki.-2012.3.-C. 108-148. DOI: 10.7256/2305-9699.2012.3.240. URL: http://www.e-notabene.ru/lr/article_240.html

12. Shchuplenkov O.V., Shchuplenkov N.O. Transformatsiya vlasti v protsesse postroeniya grazhdanskogo obshchestva v Rossii // NB: Problemy obshchestva i politiki.-2013.-9.-C. 20-88. URL: http://www.e-notabene. $\mathrm{ru} / \mathrm{pr} /$ article_9053.html

13. Shchuplenkov O.V., Shchuplenkov N.O. Idei solidarizma v kontseptsii postroeniya grazhdanskogo obshchestva v Rossii // NB: Problemy obshchestva i politiki.-2013.-8.-C. 72-137. URL: http://www.e-notabene.ru/pr/ article_8750.html

14. M. M. Vakhitov Uchastie grazhdan Rossiiskoi Federatsii v regional'nom pravotvorchestve: priroda i mekhanizmy realizatsii // Politika i Obshchestvo.-2011.-11.-C. 113-127. 